\title{
ORIGINAL ARTICLE \\ Do we have an ideal classification system for thoracolumbar and subaxial cervical spine injuries: what is the expert's perspective?
}

\author{
HS Chhabra, R Kaul ${ }^{1}$ and V Kanagaraju ${ }^{1}$
}

\begin{abstract}
Study design: Online questionnaire survey.
Objective: To obtain the opinion of experts on whether the currently available classification systems for thoracolumbar and subaxial cervical spine injuries meet their expectations with regard to the desired objectives of a good classification system and practical implementability.

Methods: An online survey was conducted during August-September 2013 using a specially designed questionnaire. Members of Spine Trauma Study Group of International Spinal Cord Society and other spinal injury experts were approached, and responses were analyzed.

Results: Forty-two spine experts responded. Majority $(87.50 \%, n=35)$ were involved with education and research. For subaxial cervical spine injuries, Allen Ferguson classification was more commonly used $(37.50 \%, n=15)$ and thought to be practically implementable in day-to-day practice (30.77\%). For thoracolumbar injuries, while Thoracolumbar Injury Classification and Severity Score (TLICS) was more commonly used $(47.50 \%, n=19)$, the response of experts for practical implementability in day-to-day practice was more evenly distributed among TLICS, AO (Association for Osteosynthesis) and Dennis classifications (30.77, 23.08 and 25.64\%, respectively). Experts felt that the classification systems did not serve all the desired objectives. The reliability for residents was especially a concern.

Conclusion: We may still be far from an ideal classification system. Many experts continue to prefer or would consider shifting back to traditional and simpler systems. There is a need for developing classification systems that would be better implementable practically in day-to-day clinical practice, better guide treatment, be more reliable, incorporate other modifiers influencing treatment and be more comprehensive in that order of priority.
\end{abstract}

Spinal Cord (2015) 53, 42-48; doi:10.1038/sc.2014.194; published online 11 November 2014

\section{INTRODUCTION}

Classification systems are helpful to identify common attributes within a group to predict the behavior or outcome without sacrificing too much detail. The need of a classification system which is clinically relevant, reliable and accurate is well documented ${ }^{1}$ as are the expectations from an ideal one. ${ }^{2}$ Numerous classification systems based on various parameters such as fracture morphology, mechanism of injury, anatomical determinants of fracture stability and neurological status have been proposed to describe thoracolumbar and subaxial cervical spine injuries. ${ }^{3,4}$

Earlier classifications have been based on assumed mechanism of injury implied from plain radiographs, ignoring the contribution of ligaments to stability and failing to account for underlying neurologic injury. ${ }^{5}$ Others have been cumbersome and difficult to apply, if not impractical. Each of them claims to be better than the previous ones. However, studies have pointed out some inherent limitations even in the most recent classification systems. ${ }^{5}$

For subaxial cervical injuries, Holdsworth ${ }^{6}$ proposed a classification, based on two-column concept of stability, emphasizing the importance of posterior ligamentous complex and the morphology of facet joint sustaining violence. But it was not done systematically, and it was therefore not possible to control and review his observations. Allen Ferguson (AF) classification was formulated based on a study of 165 acute spinal cord injury patients. The classification system was based on the belief that translation of kinetic energy into fractures and dislocations is determined by two independent variables: injury vector and the posture of the cervical spine at the time of accident. No measurement of reliability or validity were undertaken. ${ }^{7}$ Harris et al. ${ }^{8}$ introduced another mechanistic classification of subaxial cervical spine injuries based on biomechanical, cadaveric and pathological evidence of vector forces that act on cervical spine during injuries. No measurement of reliability or validity were undertaken. The classification also does not guide treatment and does not predict outcome. The Cervical Spine Injury Severity Score (CSISS) as presented by Moore et al. allows the classification of injury by radiological findings and fracture stability. It does not include neurological function in the classification but guides treatment. ${ }^{9,10}$ The Subaxial Cervical spine Injury Classification and Severity Score (SLIC) system, presented by Vaccaro et al., ${ }^{11}$ allows for a grading of severity both from a radiological and neurological perspective. It can guide treatment based 
on the SLIC score. However, the system fares worse than the AF and Harris system with regard to reliability. ${ }^{11,12}$

Among various existing classification systems for thoracolumbar spine injuries, only few have been assessed for reliability, reproducibility or clinical validity. ${ }^{13}$ The three-column-model-based Denis classification is among the commonly used, is easily reproducible and has good acceptance in many centers because of its simplicity. ${ }^{14}$ However, it does not account for all fracture types or the neurological status of the patient and lacks predictive value to aid treatment decisions. $^{3}$ The AO-Magerl classification was more inclusive by identifying a wide array of fractures, including $>50$ subtypes using the 3-3-3 AO principle leading to its complexity, limiting its incorporation into routine clinical practice. ${ }^{3,15}$ In addition, it also does not account for neurological status, a critical determinant for surgical decision making. ${ }^{3}$

In 2005 Spine Trauma Study Group (STSG) introduced the Thoracolumbar Injury Severity Score (TLISS), which was based on three major injury characteristics: the mechanism of injury, the integrity of the posterior ligamentous complex, and the patient's neurological status. ${ }^{16}$ Although as a whole it had an excellent construct validity, interobserver agreement for injury mechanism was only fair (kappa = 0.33). ${ }^{17-19}$ This led to introduction of the Thoracolumbar Injury Classification and Severity Score (TLICS) in which fracture mechanism was replaced by description of morphological injury. ${ }^{20}$ Others have pointed out some inherent limitations even in the recent TLICS classification system. ${ }^{3,21}$

With the advancement in imaging technologies and newer classification systems, do we have acceptable and reliable classification systems for thoracolumbar and subaxial cervical spine injuries? With this query in mind, we conducted a questionnaire survey to take the opinion of experts on whether the currently available classification systems for thoracolumbar and subaxial cervical spine injuries meet their expectations and are practically implementable within their set up.

\section{MATERIALS AND METHODS}

An online survey was conducted during August-September 2013 using a specially designed questionnaire. Surveymonkey is an online survey site that simplifies the survey process significantly. In the survey design phase, surveymonkey offers 17 formats for asking questions (multiple choice, true false, open-ended and so on). Surveymonkey has the ability to track respondents so that non-respondents can be recontacted and those who have already anticipated are not pestered. Surveymonkey can generate frequencies for each question and allows export of data into statistical software programs for more complex analysis. There were 20 questions in the whole questionnaire. All questions were multiple choices, close ended (except the question asking the name of respondents) and there was no space to add comments. For all the 15 questions, experts could select one answer, whereas for 4 questions there were multiple options. It was not mandatory for experts to respond to all questions, and they could finish the questionnaire without completing all the answers. The first part of the questionnaire dealt with the clinical practice of the experts, enquiring on the percentage of spine and spine trauma patients in their practice and whether they were involved in education and research. The next part of the questionnaire had questions pertaining to the classification system being used by experts, the desired objectives of a good classification system and those served by the ones being used by the experts, the additional information desired by experts from an ideal classification system as well as ease of use of the classification systems by students/fellows. The questions of the questionnaire have been enlisted in Table 1. A pilot testing was done on three experts to check the clarity of questions, time required to complete the questionnaire and the relevance of all questions. All 28 experts of STSG of International Spinal Cord Society (ISCoS) and 42 other experts known to be actively involved in spinal injury management were approached through an e-mail for participation in this
Table 1 Questions of the specially designed questionnaire used for the survey

\section{S. no. Questions}

$1 \quad$ Please enter your name

$2 \quad$ What does your clinical practice primarily comprise of?

3 Out of all spine cases being dealt in your department in a year, what is the approximate percentage of spine fracture cases?

$4 \quad$ In addition to service delivery, is your department involved in education and research also?

5 Which classification system is being used in your department for classifying thoracic, thoracolumbar or lumbar fractures?

$6 \quad$ Which classification system is being used in your department for classifying cervical spine fractures?

7 According to you, what are the desired objectives of a good classification system?

8 Which of the desired objectives are being served by the classification system that you use for thoracolumbar spine?

9 Which of the desired objectives are being served by the classification system that you use for cervical spine?

10 What percentage of thoracic, thoracolumbar and lumbar spine trauma cases being managed at your department are the junior residents or postgraduate students able to classify as per the classification system being used in your department?

11 What percentage of cervical spine trauma cases being managed at your department are the junior residents or postgraduate students able to classify as per the classification system being used in your department?

12 What percentage of thoracic, thoracolumbar and lumbar spine trauma cases being managed in your department are the spine fellows or registrars able to classify as per the classification system being used in your department?

13 What percentage of cervical spine trauma cases being managed in your department are the spine fellows or registrars able to classify as per the classification system being used in your department?

14 What percentage of thoracic, thoracolumbar and lumbar spine trauma cases that come to your facility are routinely classified as per the classification system that you use?

15 What percentage of cervical spine trauma cases that come to your facility are routinely classified as per the classification system that you use?

16 What additional information do you desire from the classification system being used by you?

17 For what percentage of thoracic, thoracolumbar \& lumbar spine fracture cases coming to your facility does the classification system being used by you, guide you for its management

18 For what percentage of cervical spine fracture cases coming to your facility does the classification system being used by you, guide you for its management

19 According to you, which classification system for classifying thoracic, thoracolumbar or lumbar fractures is practically implementable in your dayto-day practice?

20 According to you, which classification system for classifying cervical fractures is practically implementable in your day-to-day practice?

study. Non-respondents were tracked through surveymonkey and re-contacted. The responses were analyzed from 23 September to 16 December 2013, and only descriptive data are reported. Preplanned comparisons on the choice of classification systems were done using the Fisher Exact Probability test made between respondents who had exclusive spine-related clinical practice versus who do not; who treat either low (0-25\%), moderate (26-50\%), high (51$75 \%)$ or very high $(76-100 \%)$ number of spine fracture cases and who are involved in academics/research versus who do not. Choices were also compared across exclusive/substantial/occasional spine centers. 


\section{RESULTS}

The pilot testing done on three experts established clarity and relevance of all questions. Mean time required to complete the questionnaire was $14 \mathrm{~min}$. Out of the 70 experts who were approached to fill the questionnaire of the online survey, only 42 responded (16 experts were members of STSG of ISCoS, whereas 26 were other spine surgeons) despite reminder to non-respondents.

Their clinical practice comprised of exclusively spine patients in $45.23 \%(n=19)$, substantially spine patients in $38.1 \%(n=16)$ and often spine patients in $12 \%(n=5)$. Those whose practice comprised of occasionally spine patients $(4.8 \%, n=2)$ were excluded from the study. Of all the spine cases being dealt by their department in a year, approximate percentage of spine fracture cases were in range of $0-25 \%$ for $50 \%(n=20)$ experts, $26-50 \%$ for $32.50 \%(n=13)$ experts, $51-75 \%$ for $12.50 \%(n=5)$ experts and $76-100 \%$ for $5 \%(n=2)$ experts. Apart from their routine clinical practice, about $87.50 \%$ $(n=35)$ experts were also involved with education and research. The details of the classification system used by the experts in their department for thoracolumbar and subaxial cervical spine injuries are given in Table 2. There were statistically no difference on the choice of thoracic or thoracolumbar or lumbar classification systems or cervical classification systems across exclusivity of clinical practice ( $P=0.83$ and $P=0.13$, respectively), relative percentages of spine fracture cases treated $(P=0.29$ and $P=0.34$, respectively) or involvement in academics/research $(P=0.82$ and $P=0.53$, respectively). The experts' perspective of desired objectives of a good classification system

Table 2 Classification system used by the experts in their department for classifying subaxial cervical spine and thoracolumbar spine injuries

\begin{tabular}{lclc}
\hline $\begin{array}{l}\text { Subaxial cervical spine } \\
\text { injury classifications }\end{array}$ & $\begin{array}{c}\text { Percentage of } \\
\text { experts }\end{array}$ & $\begin{array}{l}\text { Thoracolumbar spine } \\
\text { injury classifications }\end{array}$ & $\begin{array}{r}\text { Percentage } \\
\text { of experts }\end{array}$ \\
\hline Allen Ferguson & 37.50 & Dennis classification & 20 \\
SLIC & 35 & AO-Magerl & 25 \\
CSISS & 5 & Classification & 47.5 \\
Any other & 7.50 & Any other & 2.50 \\
None & 15 & None & 5 \\
\hline
\end{tabular}

Abbreviations: AO, Association for Osteosynthesis; CSISS, Cervical Spine Injury Severity Score; SLIC, Subaxial Cervical Spine Injury Classification and Severity Score. TLICS, Thoracolumbar Injury Classification and Severity Score.

Table 3 Expert's perspective on desired objectives of a good classification system

\begin{tabular}{lc}
\hline Objectives (desired of a good classification sysytem) & $\begin{array}{c}\text { Percentages } \\
\text { of experts }\end{array}$ \\
\hline $\begin{array}{l}\text { Allows identification of any kind of spine injury and offers concise } \\
\text { terminology, thus providing an effective tool for communication } \\
\text { and documentation }\end{array}$ & 78.95 \\
$\begin{array}{l}\text { Provides information regarding injury mechanism and severity } \\
\text { of both bony and ligamentous injury }\end{array}$ & 73.68 \\
$\begin{array}{l}\text { Takes into consideration pattern of neurological injury and } \\
\text { grades its severity }\end{array}$ & 65.79 \\
Predicts natural history & 34.21 \\
Guides choice of treatment & 76.32 \\
Provides tool for future studies & 52.63 \\
\hline
\end{tabular}

and those served by the classification system being used by the experts are given in Table 3 and Tables $4 \mathrm{~A}$ and $\mathrm{B}$, respectively. The opinion of experts with regard to ability of junior residents/postgraduate students and fellow/registrar to classify subaxial cervical and thoracolumbar spine injuries as per the classification system being used in their department is given in Table 5. The views of experts on classification system practically implementable in day-to-day practice and additional information desired by the experts from a classification system over

Table 4A Expert's perspective on objectives being served by the thoracolumbar spine injury classification system being used in their department

Objectives

Served by the thoracolumbar spine injury

classification used by the expert

\begin{tabular}{|c|c|c|c|c|}
\hline & $A O$ & Denis & TLICS & Overall \\
\hline $\begin{array}{l}\text { Illows identification of any kind } \\
\text { f spine injury and offers concise } \\
\text { erminology, thus providing an } \\
\text { ffective tool for communication } \\
\text { nd documentation }\end{array}$ & $10(100 \%)$ & $6(75 \%)$ & $13(68.4 \%)$ & $72.50 \%$ \\
\hline $\begin{array}{l}\text { Provides information regarding } \\
\text { injury mechanism and severity of } \\
\text { both bony and ligamentous injury }\end{array}$ & $5(50 \%)$ & $4(50 \%)$ & $15(79 \%)$ & $62.50 \%$ \\
\hline $\begin{array}{l}\text { Takes into consideration pattern of } \\
\text { neurological injury and grades its } \\
\text { severity }\end{array}$ & $2(20 \%)$ & $1(12.5 \%)$ & $14(74 \%)$ & $42.50 \%$ \\
\hline Predicts natural history & $3(30 \%)$ & 0 & $1(5.3 \%)$ & $12.50 \%$ \\
\hline Guides choice of treatment & $6(60 \%)$ & $2(25 \%)$ & $11(58 \%)$ & $52.50 \%$ \\
\hline Provides tool for future studies & $4(40 \%)$ & $1(12.5 \%)$ & $5(26.3 \%)$ & $25 \%$ \\
\hline
\end{tabular}

Table 4B Expert's perspective on objective being served by the sub-axial cervical spine injury classification system being used in these departments

\begin{tabular}{|c|c|c|c|c|}
\hline \multirow[t]{2}{*}{ Objectives } & \multicolumn{4}{|c|}{$\begin{array}{l}\text { Served by subaxial cervical spine injury } \\
\text { classification used by the experts }\end{array}$} \\
\hline & SLIC & CSISS & $\begin{array}{l}\text { Allen } \\
\text { Ferguso }\end{array}$ & Overall \\
\hline
\end{tabular}

Allows identification of any kind of

$10(71.4 \%) \quad 1$ (50\%) $12(80 \%) \quad 72.50 \%$ spine injury and offers concise terminology, thus providing an effective tool for communication and documentation

Provides information regarding injury $10(71.4 \%) \quad 1(50 \%) \quad 12(80 \%) \quad 70.00 \%$ mechanism and severity of both bony and ligamentous injury Takes into consideration pattern of $\quad 8(57.1 \%) \quad 1(50 \%) \quad 3(20 \%) \quad 37.50 \%$ neurological injury and grades its severity

$\begin{array}{llll}2(14.3 \%) & 0 & 3(20 \%) & 17.50 \% \\ 9(64.3 \%) & 0 & 7(47 \%) & 47.50 \% \\ 4(29 \%) & 0 & 3(20 \%) & 20.00 \%\end{array}$
Guides choice of treatment Provides tool for future studies 
Table 5 The opinions of experts with regard to the ability of junior residents/postgraduate students and fellows/registrars to classify subaxial cervical spine and thoracolumbar spine injuries as per the classification system being used in their department

What percentage of cervical spine trauma cases being managed at your department are the junior residents or postgraduate students able to classify as per the classification system being used in your department?

\begin{tabular}{lccccc}
\hline $\begin{array}{l}\text { Junior residents/ } \\
\text { postgraduates students }\end{array}$ & $\begin{array}{c}\text { Allen Ferguson } \\
(\mathrm{n}=16)\end{array}$ & $\begin{array}{c}\text { CSISS } \\
(\mathrm{n}=2)\end{array}$ & $\begin{array}{c}\text { SLIC } \\
(\mathrm{n}=13)\end{array}$ & $\begin{array}{c}\text { None } \\
(\mathrm{n}=6)\end{array}$ & $\begin{array}{c}\text { Any other } \\
(\mathrm{n}=3)\end{array}$ \\
\hline$<85$ & $81.2 \%$ & $50 \%$ & $69.23 \%$ & $83.3 \%$ & $33.3 \%$ \\
$85-90$ & $12.5 \%$ & 0 & $23.1 \%$ & 0 & $33.3 \%$ \\
$90-95$ & $6.25 \%$ & $50 \%$ & $7.7 \%$ & $17 \%$ & $33.3 \%$ \\
$95-100$ & 0 & 0 & 0 & 0 & 0 \\
\hline
\end{tabular}

What percentage of cervical spine trauma cases being managed in your department are the spine fellows or registrars able to classify as per the classification system being used in your department?

\begin{tabular}{lccccc}
\hline $\begin{array}{l}\text { Senior } \\
\text { fellows }\end{array}$ & $\begin{array}{c}\text { Allen Ferguson } \\
(\mathrm{n}=13)\end{array}$ & $\begin{array}{c}\text { CSISS } \\
(\mathrm{n}=2)\end{array}$ & $\begin{array}{c}\text { SLIC } \\
(\mathrm{n}=13)\end{array}$ & $\begin{array}{c}\text { None } \\
(\mathrm{n}=6)\end{array}$ & $\begin{array}{c}\text { Any other } \\
(\mathrm{n}=2)\end{array}$ \\
\hline$<85$ & $23.1 \%$ & $50 \%$ & $31 \%$ & $33.3 \%$ & $50 \%$ \\
$85-90$ & $46.15 \%$ & 0 & $38.5 \%$ & $16.7 \%$ & 0 \\
$90-95$ & $31 \%$ & $50 \%$ & $23.1 \%$ & 0 & 0 \\
$95-100$ & 0 & 0 & $8 \%$ & $50 \%$ & $50 \%$ \\
\hline
\end{tabular}

What percentage of cervical spine trauma cases which come to your facility are routinely classified as per the classification system that you use?

\begin{tabular}{lccc}
\hline & Allen Ferguson $(\mathrm{n}=19)$ & CSISS $(\mathrm{n}=5)$ & SLIC $(\mathrm{n}=16)$ \\
\hline$<25 \%$ & 0 & 0 & $19 \%$ \\
$25-50 \%$ & 0 & 0 & 0 \\
$50-75 \%$ & $15.7 \%$ & $20 \%$ & $12.5 \%$ \\
$75-90 \%$ & $37 \%$ & $80 \%$ & $19 \%$ \\
$90-100 \%$ & $37 \%$ & 0 & $37.5 \%$ \\
$100 \%$ & $10.5 \%$ & 0 & $12.5 \%$ \\
\hline
\end{tabular}

What percentage of thoracic, thoracolumbar and lumbar spine trauma cases being managed at your department, are the junior residents or postgraduate students able to classify as per the classification system being used in your department?

\begin{tabular}{lccccc}
\hline $\begin{array}{l}\text { Junior } \\
\text { fellows }\end{array}$ & $\begin{array}{c}A O \\
(\mathrm{n}=10)\end{array}$ & $\begin{array}{c}\text { Dennis } \\
(\mathrm{n}=8)\end{array}$ & $\begin{array}{c}\text { TLICS } \\
(\mathrm{n}=19)\end{array}$ & $\begin{array}{c}\text { None } \\
(\mathrm{n}=2)\end{array}$ & $\begin{array}{c}\text { Any other } \\
(\mathrm{n}=1)\end{array}$ \\
\hline$<85$ & $60 \%$ & $62.5 \%$ & $47.4 \%$ & 0 & 0 \\
$85-90$ & $20 \%$ & 0 & $42.1 \%$ & 0 & 0 \\
$90-95$ & 0 & $25 \%$ & 0 & 0 & 0 \\
$95-100$ & 0 & 0 & $5.3 \%$ & 0 & 0 \\
\hline
\end{tabular}

What percentage of thoracic, thoracolumbar and lumbar spine trauma cases being managed in your department are the spine fellows or registrars able to classify as per the classification system being used in your department?

\begin{tabular}{lccccc}
\hline $\begin{array}{l}\text { Senior } \\
\text { fellows }\end{array}$ & $\begin{array}{c}\text { AO } \\
(\mathrm{n}=10)\end{array}$ & $\begin{array}{c}\text { Dennis } \\
(\mathrm{n}=8)\end{array}$ & $\begin{array}{c}\text { TLICS } \\
(\mathrm{n}=19)\end{array}$ & $\begin{array}{c}\text { None } \\
(\mathrm{n}=2)\end{array}$ & $\begin{array}{c}\text { Any other } \\
(\mathrm{n}=1)\end{array}$ \\
\hline$<85$ & $30 \%$ & $50 \%$ & $10.5 \%$ & $50 \%$ & 0 \\
$85-90$ & $20 \%$ & $37.5 \%$ & $21.05 \%$ & 0 & 0
\end{tabular}

\section{Table 5 (Continued)}

What percentage of thoracic, thoracolumbar and lumbar spine trauma cases being managed in your department are the spine fellows or registrars able to classify as per the classification system being used in your department?

\begin{tabular}{lccccc}
\hline $\begin{array}{l}\text { Senior } \\
\text { fellows }\end{array}$ & $\begin{array}{c}\text { AO } \\
(\mathrm{n}=10)\end{array}$ & $\begin{array}{c}\text { Dennis } \\
(\mathrm{n}=8)\end{array}$ & $\begin{array}{c}\text { TLICS } \\
(\mathrm{n}=19)\end{array}$ & $\begin{array}{c}\text { None } \\
(\mathrm{n}=2)\end{array}$ & $\begin{array}{c}\text { Any other } \\
(\mathrm{n}=1)\end{array}$ \\
\hline $90-95$ & $20 \%$ & 0 & $37 \%$ & 0 & 0 \\
$95-100$ & 0 & $12.5 \%$ & $26.3 \%$ & 0 & 0 \\
\hline
\end{tabular}

What percentage of thoracic, thoracolumbar and lumbar spine trauma cases which come to your facility are routinely classified as per the classification system that you use?

\begin{tabular}{lccc}
\hline & $A O(\mathrm{n}=11)$ & Dennis $(\mathrm{n}=9)$ & TLICS $(\mathrm{n}=20)$ \\
\hline$<25 \%$ & $9.09 \%$ & $22.2 \%$ & $5 \%$ \\
$25-50 \%$ & 0 & 0 & 0 \\
$50-75 \%$ & $27.2 \%$ & $11.1 \%$ & $10 \%$ \\
$75-90 \%$ & $27.2 \%$ & $22.2 \%$ & $25 \%$ \\
$90-100 \%$ & $18.1 \%$ & $44.4 \%$ & $35 \%$ \\
$100 \%$ & $20 \%$ & 0 & $15 \%$ \\
\hline
\end{tabular}

Abbreviations: AO, Association for Osteosynthesis; CSISS, Cervical Spine Injury Severity Score; SLIC, Subaxial Cervical Spine Injury Classification and Severity Score; TLICS, Thoracolumbar Injury Classification and Severity Score.

Table 6 Practical implementability of spinal injury classification systems in day-to-day clinical practice of experts

\begin{tabular}{lccc}
\hline & \multicolumn{3}{c}{ Practical implementability } \\
\cline { 2 - 4 } User & AO & Denis & TLICS \\
\hline AO $(n=10)$ & $30 \%$ & $40 \%$ & $20 \%$ \\
Denis $(n=8)$ & $25 \%$ & $37.5 \%$ & 0 \\
TLICS $(n=19)$ & $11.1 \%$ & $17 \%$ & $55.5 \%$ \\
Overall & $23.08 \%$ & $25.64 \%$ & $30.77 \%$ \\
\hline
\end{tabular}

\begin{tabular}{lccc}
\hline & \multicolumn{3}{c}{ Practical implementability } \\
\cline { 2 - 4 } User & SLIC & CSISS & Allen Ferguson \\
\hline SLIC $(n=14)$ & $57.1 \%$ & $14.3 \%$ & $7.14 \%$ \\
CSISS $(n=1)$ & 0 & 0 & 0 \\
Allen Ferguson $(n=15)$ & $13.3 \%$ & 0 & $66.7 \%$ \\
Overall & $25.64 \%$ & $7.69 \%$ & $30.77 \%$ \\
\hline
\end{tabular}

Abbreviations: AO, Association for Osteosynthesis; CSISS, Cervical Spine Injury Severity Score; SLIC, Subaxial Cervical Spine Injury Classification and Severity Score; TLICS, Thoracolumbar Injury Classification and Severity Score.

and above that being provided by the one that they use are summarized in Tables 6 and 7, respectively.

\section{DISCUSSION}

Many of the experts who responded to the online questionnaire survey were members of STSG of ISCoS, and majority $(87.50 \%, n=35)$ were involved with education and research also. Most of them had practice exclusively $(45.23 \%, n=19)$ or substantially $(38.09 \%, n=16)$ in spine. 
Table 7 Additional information desired by the experts from a classification system over and above that being provided by the one that they use

\begin{tabular}{lc} 
Additional information desired & Response \\
\hline Should be more comprehensive & $34.21 \%$ \\
Should be implementable practically during day-to-day clinical & $71.05 \%$ \\
practice & \\
Should incorporate other modifiers that may influence treatment plan & $44.74 \%$ \\
Able to effectively guide treatment plan & $68.42 \%$ \\
Better interobserver and intraobserver reliability & $47.37 \%$ \\
None & $0 \%$ \\
\hline
\end{tabular}

Thus they were the appropriate experts to provide information for which study was designed.

A good classification system should be straightforward, easy to use for all concerned and practically implementable in day-to-day practice. In addition, it should be replicable, that is, having a good interobserver and intraobserver reliability. ${ }^{1}$ The desired objectives of a good spinal injury classification system have been well described in the literature. ${ }^{2}$

The experts were of the opinion that classification systems being used by them did not serve all the desired objectives. Vast majority of experts felt that these classification systems could not predict natural history $(87.50 \%$ and $82.50 \%)$ or provide tool for future studies $(75 \%$ and $80 \%$ ) for thoracolumbar and subaxial cervical spine injuries, respectively. Almost more than half felt that these systems did not take into consideration patterns of neurological injury and grade its severity $(57.50 \%$ and $62.50 \%)$ or appropriately guide choice of treatment (47.50\% and $52.50 \%$ ) for thoracolumbar and subaxial cervical spine injuries, respectively. A further analysis revealed that none of the classification systems could meet the desired objectives appropriately. Thus there is a need for classification system that would better meet these objectives. The available literature also mentions similar observations. ${ }^{1}$

Even though Denis classification for thoracolumbar spine injuries has good acceptance and is easily reproduced because of its simplicity, it is not detailed enough to account for all fracture types. In addition, it neither provides prognostic information nor accounts for the neurological status of the patient and, therefore, does not adequately guide surgical decision making. ${ }^{22}$ The original concept of instability has been oversimplified to state that it exists if two of three columns are disrupted, thus requiring operative stabilization in these cases. Several studies have, however, shown that non-operative treatment of two-column injuries may achieve a satisfactory outcome. ${ }^{23,24} \mathrm{AO}$ thoracolumbar injury classification system identifies a wide array of fractures, including $>50$ subtypes. However, its complexity has yielded low interobserver and intraobserver agreement. ${ }^{25-27}$ In addition, the AO system does not account for the patient's neurological status, a critical determinant of surgical decision making. ${ }^{22}$ TLICS, the most recent classification system for thoracolumbar spine injuries, also has its limitations. Most of the investigations with regard to it have been performed by individuals who were involved with its development, and majority of the published data is based on retrospective studies. Prospective application, with a direct comparison with other classification systems, is needed to clarify the relative and absolute efficacy of the TLICS. There are certain injury patterns that may be difficult to classify and score. ${ }^{3,28}$ The reproducibility and feasibility of evaluating posterior ligamentous complex integrity using magnetic resonance imaging has also been questioned. ${ }^{29}$
Similarly for lower cervical spine injuries also the literature suggests that in the absence of an ideal system we persist in using generally accepted injury description, and this needs further refinement. ${ }^{30}$ Traditional classification of subaxial cervical spine injuries, including the AF system, remains primarily descriptive. Even for the most recent classification system, that is, SLIC, the experts behind the system agree to its limitations. Better definitions of discoligamentous complex status through further research will be expected to improve the reliability of this system. There is also significant disagreement in fracture morphology. This may be due to difficulties in converting from non-uniform, descriptive systems to the current SLIC system. ${ }^{31}$

When it comes to ease of use by all concerned, most experts $(64 \%$ and $78.4 \%$ ) in the study felt that $<85 \%$ of junior residents or postgraduate students are able to classify as per the thoracolumbar and subaxial cervical spine classification system being followed by the department, respectively. When it came to spine fellows and registrars, many experts $(28.57 \%$ and $30.58 \%)$ felt that $<85 \%$ were able to classify as per the thoracolumbar and subaxial cervical spine classification system being followed by the department, respectively. Considering that the vast majority of the experts were from departments exclusively or substantially dealing with spinal ailments and were involved in education and research as well, using the currently available classification systems would be more challenging for residents in non-teaching facilities, which together cater to a probably much larger percentage of patients.

The literature also depicts a similar scenario on comparing the reliability of three thoracolumbar injury classification systems (Denis, $\mathrm{AO}$ and TLISS). The study by Lenarz et al. ${ }^{32}$ was on the objective to compare and evaluate the reliability of the Denis, AO and TLISS classification systems. They concluded that the highest reliability was for the attending and senior resident group (kappa $=0.71,0.79,0.70)$ and the lowest for the junior resident and non-spine-attending surgeon group (kappa $=0.52,0.52,0.45$ ).

Bevevino's study ${ }^{33}$ examined the reliability of TLICS among orthopedic surgeons at different levels of training. The use of TLICS demonstrated moderate-to-excellent intraobserver and interobserver reliability among all training levels. Senior residents and staff demonstrated improved intraclass correlation coefficients in higher training levels; however, interns and junior residents were able to reliably classify spinal trauma injuries. This suggests that the TLICS scheme is a reliable way to successfully communicate thoracolumbar injury information.

Considering the fact that, in day-to-day practice, one of the most common uses of the classification systems may be for the junior residents/fellows to communicate to the consultant the type of injury a patient reporting in an emergency has, there is a need for a system that can also be easily and reliably used by the residents.

The experts also felt that the classification system being used by them should be more practically implementable in day-to-day practice. TLICS was being used by $47.5 \%$ of experts as against AO by $25 \%$ and Denis by $20 \%$. However, when asked as to which classification system is practically implementable in their day-to-day practice, the response of the experts was more evenly divided among TLICS, AO and Denis classification (31, 23 and 37.5\%, respectively). For the cervical spine classification system, the experts generally used the AF and SLIC (37.50\% and 35\%, respectively). When asked as to which system was practically implementable to their day-to-day practice, AF and SLIC were the choice of $31 \%$ and $26 \%$, respectively. Interestingly, $15.4 \%$ and $31 \%$ of the experts responded that none of the thoracolumbar or subaxial cervical spine classification systems, respectively, was practically implementable in day-to-day practice. 
Many experts, meanwhile, continue to prefer or are considering shifting back to traditional and simpler systems, which may be more practically implementable. This rethink has suggested that on further introspection the traditional systems may be more useful than they may have been thought to be. Nakashima et al. ${ }^{34}$ in a recent study observed that there is a statistically significant correlation ( $P$-value $<0.01)$ ) between AF's patterns and the neurological outcome and recovery rate. As the stage advanced, the neurological status on admission and final follow-up tended to be more severe. They concluded that AF's classification is also a useful system to plan a treatment strategy. ${ }^{34}$

As the experts were of the opinion that classification systems being used by them did not serve all the desired objectives and should be more practically implementable in day-to-day practice, as there was no consensus on the best classification system available as was evident from the different systems they were using and as the reliability of use by the residents has been a concern and that among experts has also not been as would be desirable, there is a need for better classification systems.

As per $71 \%$ of the experts, the most desirable feature of any such new classification system over and above the one that they were using was that it should be implementable practically during day-to-day clinical practice. This may be the reason why many experts continue to prefer or are considering shifting back to traditional and simpler systems, which are probably more practically implementable. Thus the option of suitably modifying traditional classification systems to develop a newer classification system could be explored.

The other almost equally desirable feature of a new classification system as per $68 \%$ of the experts was that it should better guide treatment. Other important features to be kept in mind while developing a new classification system would be better reliability (47\%), incorporation of other modifiers influencing treatment $(45 \%)$ and better comprehensiveness (34\%).

The involvement of experts from across the globe representing developed as well as emerging nations was the strength of the study. Though 55\% of experts did not practice spine exclusively, this may represent the emerging nation scenario. An AOSpine Thoracolumbar Spine Injury Classification System was introduced in November $2013^{35}$ after the survey had been conducted, and hence the opinion of the experts on this classification system could not be taken.

One of the limitation of the study was that the choice of responses to the question 'What additional information do you desire from the classification system being used by you?' could have been made more specific, such as outlining how the classification system could have been made more comprehensive and outlining the modifiers which when incorporated would influence the treatment plan.

\section{CONCLUSION}

Our study revealed that even though newer classification systems have come out which supposedly have improvement over the previous ones, we may still be far from the ideal one. The classification systems need to better meet the objectives as expected from an ideal system, be more reliable and repeatable (especially for residents), as well as easy to use and be practically implementable in day-to-day practice. Meanwhile, experts continue to prefer or would consider shifting back to traditional and simpler ones. There is a need for developing classification systems that would be better implementable practically in day-to-day clinical practice, better guide treatment, be more reliable, incorporate other modifiers influencing treatment and be more comprehensive in that order of priority.

\section{DATA ARCHIVING}

There were no data to deposit.

\section{CONFLICT OF INTEREST}

The authors declare no conflict of interest.

\section{ACKNOWLEDGEMENTS}

We thank all members of the Spine Trauma Study Group of International Spinal Cord Society and other experts who participated in the survey. We also acknowledge the help of other consultants of the Spine Service of Indian Spinal Injuries Centre, namely, Dr Kalidutta Das, Dr B Mohapatra, Dr ML Bansal, Dr Vikas Tandon, Dr Ankur Nanda, Dr M Gururaj, Dr Nishit Patel, Dr Rajat Mahajan and Dr Abhishek Srivastava for their help in conceiving the study and preparing the manuscript.

1 van Middendorp JJ, Audigé L, Hanson B, Chapman JR, Hosman AJF. What should an ideal spinal injury classification system consist of? A methodological review and conceptual proposal for future classifications. Eur Spine J 2010; 19: 1238-1249.

2 Mirza SK, Mirza AJ, Chapman JR, Anderson PA. Classifications of thoracic and lumbar fractures: rationale and supporting data. J Am Acad Orthop Surg 2002; 10: 364-377.

3 Patel AA, Vaccaro AR. Thoracolumbar spine trauma classification. J Am Acad Orthop Surg 2010; 18: 63-71.

4 Aarabi B, Walters BC, Dhall SS, Gelb DE, Hurlbert RJ, Rozzelle CJ et al. Subaxial cervical spine injury classification systems. Neurosurgery 2013; 72: 170-186.

5 Aarabi B, Walters BC, Dhall SS, Gelb DE, Hurlbert RJ, Rozelle CJ et al. Subaxial cervical spine injury classification systems. Neurosurgery 2013; 72: 170-186.

6 Holdsworth F. Fractures, dislocations, and fracture-dislocations of the spine. J Bone Joint Surg Am 1970; 52: 1534-1551.

7 Allen BL Jr, Ferguson RL, Lehmann TR, O'Brien RP. A mechanistic classification of closed, indirect fractures and dislocations of the lower cervical spine. Spine (Phila Pa 1976) 1982; 7: 1-27.

8 Harris JH, Edeiken-Monroe B, Kopansiky DR. A practical classification of acute cervical spine injuries. Orthop Clin North Am 1986; 17: 15-30.

9 Moore TA, Vaccaro AR, Anderson PA. Classification of lower cervical spine injuries. Spine (Phila Pa 1976) 2006; 31 (11 Suppl): S37-S43.

10 Anderson PA, Moore TA, Davis KW, Molinari RW, Resnick DK, Vaccaro AR et al. Cervical spine injury severity score. Assessment of reliability. J Bone Joint Surg Am 2007; 89: 1057-1065.

11 Vaccaro AR, Hulbert RJ, Patel AA, Fischer C, Dvorak M, Lehman RA et al. Spine Trauma Study Group. The subaxial cervical spine injury classification system: a novel approach to recognize the importance of morphology, neurology, and integrity of the discoligamentous complex. Spine (Phila Pa 1976) 2007; 32: 2365-2374.

12 Stone AT, Bransford RJ, Lee MJ, Vilela MD, Bellabarba C, Anderson PA et al. Reliability of classification systems for subaxial cervical injuries. Evid Based Spine Care J 2010; 1: 19-26.

13 Bono CM, Vaccaro AR, Hurlbert RJ, Arnold P, Oner FC, Harrop J et al. Validating a newly proposed classification system for thoracolumbar spine trauma: looking to the future of the thoracolumbar injury classification and severity score. J Orthop Trauma 2006; 20: 567-572.

14 Denis F. The three column spine and its significance in the classification of acute thoracolumbar spinal injuries. Spine 1983; 8: 817-831.

15 Magerl F, Aebi M, Gertzbein SD, Harms J, Nazarian S. A comprehensive classification of thoracic and lumbar injuries. Eur Spine J 1994; 3: 184-201.

16 Vaccaro AR, Zeiller SC, Hulbert RJ, Anderson PA, Harris M, Hedlund R et al. The thoracolumbar injury severity score: a proposed treatment algorithm. J Spinal Disord Tech 2005; 18: 209-215.

17 Harrop JS, Vaccaro AR, Hulbert RJ, Wilsey JT, Baron EM, Shaffrey Cl et al. Intrarater and interrater reliability and validity in the assessment of the mechanism of injury and integrity of the posterior ligamentous complex: a novel injury severity scoring system for thoracolumbar injuries. Invited submission from the Joint Section Meeting on Disorders of the Spine and Peripheral Nerves, March 2005. J Neurosurg Spine 2006; 4: 118-122.

18 Vaccaro AR, Baron EM, Sanfilippo J, Jacoby S, Steuve J, Grossman E et al. Reliability of a novel classification system for thoracolumbar injuries: the thoracolumbar injury severity score. Spine (Phila Pa 1976) 2006; 31: S62-S69.

19 Rampersaud RY, Fisher C, Wilsey J, Arnold P, Anand N, Bono CM et al. Agreement between orthopedic surgeons and neurosurgeons regarding a new algorithm for the treatment of thoracolumbar injuries: a multicenter reliability study. J Spinal Disord Tech 2006; 19: 477-482.

20 Vaccaro AR, Lehman RA, Hulbert RJ, Anderson PA, Harris M, Hedlund R et al. A new classification of thoracolumbar injures: the importance of injury morphology, the integrity of the posterior ligamentous complex, and neurologic status. Spine 2005; 30 : 2325-2333.

21 Patel AA, Dailey A, Brodke DS, Daubs M, Harrop J, Whang PG et al. Thoracolumbar spine trauma classification: the thoracolumbar injury classification and severity score system and case examples. J Neurosurg Spine 2009; 10: 201-206. 
22 Joaquim AF, Fernandes YB, Cavalcante RA, Fragoso RM, Honorato DC, Patel AA Evaluation of the thoracolumbar injury classification system in thoracic and lumbar spinal trauma. Spine (Phila Pa 1976) 2011; 36: 33-36.

23 Ağuş H, Kayali C, Arslantaş M. Nonoperative treatment of burst-type thoracolumbar vertebra fractures: clinical and radiological results of 29 patients. Eur Spine J 2005; 14: 536-540.

24 Wood K, Buttermann G, Mehbod A, Garvey T, Jhanjee R, Sechriest V. Operative compared with nonoperative treatment of a thoracolumbar burst fracture without neurological deficit: a prospective, randomized study. J Bone Joint Surg Am 2003; 85 773-781.

25 Wood KB, Khanna G, Vaccaro AR, Arnold PM, Harris MB, Mehbod AA. Assessment of two thoracolumbar fracture classification systems as used by multiple surgeons. J Bone Joint Surg Am 2005; 87: 1423-1429.

26 Oner FC, Ramos LM, Simmermacher RK, Kingma PT, Diekerhof CH, Dhert WJ et al. Classification of thoracic and lumbar spine fractures: problems of reproducibility. A study of 53 patients using CT and MRI. Eur Spine J 2002; 11: 235-245.

27 Blauth M, Bastian L, Knop C, Lange U, Tusch G. [Inter-observer reliability in the classification of thoraco-lumbar spinal injuries] [Article in German]. Orthopade 1999; 28: 662-681.

28 Patel AA, Dailey A, Brodke DS, Daubs M, Harrop J, Whang PG et al. Thoracolumbar spine trauma classification: the Thoracolumbar Injury Classification and Severity Score system and case examples. J Neurosurg Spine 2009; 10: 201-206.
29 Rihn JA, Yang N, Fisher C, Saravanja D, Smith H, Morrison WB et al. Using magnetic resonance imaging to accurately assess injury to the posterior ligamentous complex of the spine: a prospective comparison of the surgeon and radiologist. J Neurosurg Spine 2010; 12: 391-396

30 Defino H. Lower cervical spine trauma classification systems. In: Chapman JR, Dettor JR, Norvell DC (eds). Spine Classifications and Severity Measures, 1st edn, Thieme: New York, NY, USA, 2009, pp 402-435.

31 Vaccaro AR, Hulbert RJ, Patel AA, Fisher C, Dvorak M, Lehman RA Jr et al. Spine Trauma Study Group.The subaxial cervical spine injury classification system: a nove approach to recognize the importance of orphology, neurology, and integrity of the disco-ligamentous complex. Spine (Phila Pa 1976) 2007; 32: 2365-2374.

32 Lenarz CJ, Place HM, Lenke LG, Alander DH, Oliver D. Comparative reliability of 3 thoracolumbar fracture classification systems. J Spinal Disord Tech 2009; 22: 422-427.

33 Bevevino AJ, Ronald AL, Kang DG, Cody JP, Tracey RW. The reliability of the thoracolumbar injury classification and severity score among orthopaedic surgeons at different levels of training. Scientific Poster\#168, General OTA - 2012.

34 Nakashima H, Yukawa Y, Ito K, Machino M, Kato F. Mechanical patterns of cervical injury influence postoperative neurological outcome: a verification of the Allen system. Spine (Phila Pa 1976) 2011; 36: E441-E446.

35 Vaccaro AR, Oner C, Kepler CK, Dvorak M, Schnake K Bellabarba C et al. AOSpine thoracolumbar spine injury classification system: fracture description, neurological status, and key modifiers. Spine (Phila Pa 1976) 2013; 38: 2028-2037. 